\title{
Research on Employee Relationship Management Innovation of SMEs in China
}

\author{
Jing Zhang ${ }^{1, *}$ \\ ${ }^{1}$ School of Business Administration, Shandong Institute of Commerce and Technology, Jinan, Shandong 250103, China \\ *Corresponding author. Email: 86105150@qq.com
}

\begin{abstract}
The purpose of the work is to explore the characteristics of how to improve the efficiency and effectiveness of management by researching these innovative employee relationship management applied in some small and medium-sized enterprises (SMEs) at present in China. This paper provides evidence that comprehensive incentive mechanism will promote the harmonious relationship between employees and employers from a single incentive mode to multidimensional inspiring system, instead of the traditional compensation system. The result shows the existing deficiencies of human resource management and tries to indicate the functions of non-economic reward during the whole process of organizational behaviour. The paper concludes that SMEs' sustainable developments rely on employee relationship management which provides effective protection during the competition of the market, not only domestic but also the whole world. The new perspective of this paper is to establish an incentive ecosystem to improve the employee relationship management of SMEs.
\end{abstract}

Keywords: small and medium-sized enterprises; employee relationship; management innovation; human

resource management; incentive ecosystem

\section{INTRODUCTION}

There is considerable evidence that small and mediumsized enterprises (SMEs) have a number of behavioral advantages in the innovation process, such as rapid response to threats and opportunities, efficient internal communication and interactive management style. According to Ministry of Industry and Information Technology, "12th Five Year Plan for small and mediumsized enterprises (SMEs)" points out those SMEs are the important factors for economic and social development. During the period of the "11th Five Year Plan", more than $80 \%$ of employment opportunities in urban are provided by SMEs, which becomes the main channel for recruiting new employees, including laid-offs, graduates and surplus labor force. After the issue of "Labor Contract Law" in 2008, employee relationship management has become the focus of human resource management for SMEs, whose existed problems bring in some new challenges. The purpose of human resource management is to achieve the organization goal by fully developing the employees' potential ability. While the improvement of employees' work performance mainly depends on the incentive mechanism which plays important role in SMEs at present, varies from traditional methods by using a single performance appraisal system to the innovative ecosystem during the whole process of management.

\section{NOTION OF THE EMPLOYEE RELATIONSHIP MANAGEMENT (ERM)}

\subsection{The Definition of ERM}

The definition of employee relationship management (ERM) was originally from the management of labor and capital. After several evolutions, it becomes the critical component of modern human resource management system--Employee Relationship Management.

Employee relationship is the sum of management between corporate and its constituencies, especially employee and employer. It is recognized by its cooperation, conflicts in front of the power. At the same time, it will be affected by the certain society's economy, technology, policy and culture. It aims at the study of behaviors of employment. And it emphasizes that the internal relationship should be focused on staff that represents the spirit of teamwork and harmony. So, employee relationship management of SMEs can be defined as small scale economic organizations, compared with large enterprises, establish social relations with employees during the process of production. 


\subsection{The goal of ERM}

With the arrival of the era of the knowledge economy, SMEs begin to pay attention to establish, maintain and improve the relationship between employees instead of these previous extensive ways. Employee Relationship Management is the process of adopting various controlling methods and practices to regulate the relations between company vs. staff and employee vs. employee, and enables the company to achieve its goals. Employee Relationship Management of SMEs runs through all aspects of human resource management, starting from the very first day when newer come to work. The goal of ERM is to create a good relationship that enables employees to work wholeheartedly to achieve the organization's strategy. There are 6Ms around the ERM, management of labor relations, management of interpersonal relationship, management of communication, management of mood, management of corporate culture, and management of supporting. (Table I).

Table 1. 6Ms of Employee Relationship Management

\begin{tabular}{|c|c|c|}
\hline \multicolumn{3}{|c|}{ 6Ms of Employee Relationship Management } \\
\hline CONTENTS & Descriptions & Rank \\
\hline $\begin{array}{l}\text { Management of labor } \\
\text { relationship }\end{array}$ & $\begin{array}{l}\text { To handle labor disputes } \\
\text { To interview before laid-off } \\
\text { To solve the complaints } \\
\text { To improve personnel } \\
\text { system }\end{array}$ & 6 \\
\hline $\begin{array}{l}\text { Management of } \\
\text { employee relationship }\end{array}$ & $\begin{array}{l}\text { To build up a good } \\
\text { circumstance } \\
\text { To create a proper relation } \\
\text { between superiors and } \\
\text { subordinates }\end{array}$ & 5 \\
\hline $\begin{array}{l}\text { Management of } \\
\text { communication }\end{array}$ & $\begin{array}{l}\text { To guide the dual-way } \\
\text { communication } \\
\text { To improve the feedback } \\
\text { system. }\end{array}$ & 4 \\
\hline Management of mood & $\begin{array}{l}\text { Mainly employees of mind, } \\
\text { emotions and Job } \\
\text { satisfaction } \\
\text { Job security } \\
\text { Healthcare }\end{array}$ & 3 \\
\hline $\begin{array}{l}\text { Management of } \\
\text { Corporate Culture }\end{array}$ & $\begin{array}{l}\text { To promote corporate } \\
\text { culture } \\
\text { To maintain good corporate } \\
\text { image } \\
\text { To follow corporate vision }\end{array}$ & 2 \\
\hline $\begin{array}{l}\text { Management } \\
\text { Supporting }\end{array}$ & $\begin{array}{l}\text { To offer the legal aid } \\
\text { To provide consulting } \\
\text { services }\end{array}$ & 1 \\
\hline
\end{tabular}

\section{ERM AND SMES}

The relationship between employee and employer is viewed as one of the important social relations, and also an influential factor when improving the business long-term performance. The harmony of small and medium-sized enterprises derives from the coincidence with the environment, stakeholders and investors. There is a significant relationship between employment practices and opportunities for career growth of agency workers in the employment relationship [1].

\subsection{Great significance for long-term development}

The economic power of SMEs is not as strong as SOEs (State Owned Enterprise), the anti-risk ability is weak, and the market share is not big. It will become a crucial issue that SMEs should reduce the cost, enlarge the market share and attract the investment from constituencies, at the same time they should guarantee the high quality of their products, and gain the loyalty of the customer. To achieve these goals, SMEs need to improve the relationship with their employees who are always images of the company. If they are not satisfied with their workplace and could not concentrate on the jobs, they may ruin the reputation of the corporate. Therefore, SMEs should pay much more attention to ERM to build up a good environment, to supply any kind of assist for their work and lives, and to ensure job security. It will help corporate to optimize the relationship with employee, and to contribute the foundation for long-term development.

\subsection{Good for Mental and Physical Health}

The psychological state will be a greater impact on the development of the individual and the corporate itself. In front of the stresses and strains of job, society, and salary, employees are overwhelmed psychologically. The extreme psychological sub-health phenomenon - "Foxconn 13 jump" alarms the SMEs to reflect on its behavior about how to protect employees. After this kind of psychological crisis occurred, a sense of belonging and a sense of identity upended from the bottom of the staff, at the same time they would tend to doubt both the vision and the mission on which they have a strong belief previously. So, it is obvious that for corporate to fulfill immediately is to improve employee relations, to keep the conflict between employees and managers in balance. Early intervention following the occupational injury can improve health outcomes and reduce the duration and cost of workers' compensation claims [2]. Besides this, enterprises should help employees to develop the ability of emotional control to release the pressure by them, as well as to create a safe, healthy and comfortable working environment.

\subsection{Benefit for employer-brand creation}

Employer brand is the sum perception of its image and reputation recognized by the public and internal staff China's annual Best Employers (2019) Award, sponsored by. Peking University Corporate Social Responsibility and Employer Brand Communication Research Center and Zhaopin.com, based on the data of 3581 internal staff, 
shows that the most relevant factors with brand are no longer the salary and training opportunity, but the employer commitment, organizational management and other flexible indexes, for instance, the top ten factors are sound communication mechanism, employee participation, an achievement the commitment to employees and fair and reasonable distribution system, respect for employees. Standard management system, attract talented employees positively, corporate culture, good cooperation, career planning. (see Table II).

Table 2. Internal Factors of the Best Employers

\begin{tabular}{|l|c|c|}
\hline \multicolumn{3}{|c|}{ Internal Factors of the Best Employers } \\
\hline \multicolumn{1}{|c|}{ Index } & Coefficient & Rank \\
\hline Sound communication mechanism & 0.6688 & 1 \\
\hline Employee participation & 0.6688 & 2 \\
\hline Employee commitment & 0.6555 & 3 \\
\hline Fair and reasonable distribution system & 0.6460 & 4 \\
\hline Respect for employees & 0.6365 & 5 \\
\hline Standard management system & 0.6160 & 6 \\
\hline Attract talented employees positively & 0.5984 & 7 \\
\hline Corporate culture & 0.5984 & 8 \\
\hline Good cooperation & 0.5984 & 9 \\
\hline Career planning & 0.5925 & 10 \\
\hline
\end{tabular}

Resource: China's annual best employers(2019)

Although the "Best Employers" keep changing, a good company's intrinsic qualities would not change over time. Those companies, with a good reputation, emphasizing truthful communication and transparency, are more likely to be successful, because they not only offer attractive salaries and allowances, but also let employees feel independent, and get sufficient attention. Job insecurity originates in the individual's perceptions of job insecurity and subsequently expand to include perceptions of a job insecurity climate at the workplace [3]. Although job insecurity climate has not been empirically examined, the contexts exist in some organizations where layoffs have occurred [4]. Sound ERM enables SMEs to build up good external employer brand image, and attract intelligence effectively to join. It may maintain the stability and loyalty of the core staff, and reduce the staff turnover rate, in the human resources market; it has gained a competitive advantage to promote the continuous improvement of SMEs performance.

\subsection{Improvement of Understanding and Trusting}

Employee relationship management is an important method and process for building up a nice psychological contract. SMEs managers should communicate effectively with employees in order to increase job satisfaction, support the organizational goals. Good ERM may improve the understanding and trust among employees, managers and enterprises. In this case, it may also enhance mutual trust and cooperation, and develop team spirit which may enable organizations to be successful in the fierce competition. The relationships that social and economic exchanges, two elements of the employee-organization relationship (EOR), had with affective commitment, turnover intentions, employer trust, and altruism [5]. Both organization and employees should take mutual trust as the bottom line, and build a platform with effective communication to form the core competition in an automatic way. The only way to achieve this goal is not only to set up an ecosystem of innovative management, also to promote harmony in relations among internal parties, groups and religions, which plays an irreplaceable role in enhancing unity and pooling strengths.

\section{ESTABLISHING AN INNOVATIVE ERM}

The business environment is constantly changed. No matter what kind of corporation you are, a larger one or a small one, needs to communicate strategically. SMEs policymakers and managers at all levels should introduce people-oriented concept during the process of management, establish a full range of incentives, and improve the internal communication channel, and encourage employees to develop practical career planning. It may raise the satisfaction and stability by building up staff's sense of honor, responsibility, and sense of belonging

\subsection{Establishing a Harmonious People- Oriented Relationship}

Employees are the basic elements for the survival and development of SMEs, which should change the traditional style of management, correctly grasp the characteristics of labor relations, take the staff as a starting point to provide employees with guaranteed labor relations under the conditions to the extent permitted by law, to take effective measures to improve job satisfaction, and create a fair competitive environment, and to ensure the legitimate rights and interests of enterprises and workers.

SMEs need to actively create good conditions for employee relationship management, such as building a harmonious corporate culture, improving the main content of human resource management, establishing a clear division of the organization and so on. Employee Assistance Program (EAP) may increase employee's occupational mental health care to carry out psychological services. the implementation of both material and spiritual assistants would help them to be employees' close friends. It is so important to focus on employee health, relieve employee stress, and promote the comprehensive development that encourages them to contribute their creativity and enthusiasm to business performance.

\subsection{Performing a Common Corporate Culture and Vision}

Acceptance of the corporate culture and sharing common values are the prerequisite and foundation to improve the 
employee relations management system. SMEs need to form common values and code of conduct for all employees to abide by, and need to build up an acceptable teamwork spirit to encourage interactions between employees. Where there is no common vision and belief, there is no power of sustainable development. During the process of building corporate culture, SMEs must make clear that members would agree with the vision given by the top leaders to attract all to concentrate their mind to improve job performance.

\subsection{Strengthening communication and building up a feedback system}

According to the research of organizational behavior, a good employee relation depends on good communication. Many problems of SMEs are mostly due to bad communication. Good communication can promote interpersonal harmony which enables to complete the task successfully and to achieve the enterprise's performance goals.

From the first day they joined the enterprise, they will experience various forms of communication within the corporate. Induction training is a very good opportunity for them to understand all kinds of rules and regulations, to be familiar with the environment, and to meet the requirements of new job. During the process of employee growth, SMEs should show a clear position and expectations for their employee. Besides this, they should establish clear paths of career development, so employees can focus on what they are interested in, and their career plans. no matter why employees quit voluntarily or passive resignation, studies have consistently shown that one of the major causes for voluntary turnover is related to individual's relationships with their manager or supervisor. So SMEs had better understand the reasons for employee turnover, to reduce some possible misunderstandings, or to avoid employees leaving with dissatisfactions, which may ruin the corporate image and internal employee relations.

The corporate should build up a kind of two-way feedback system. That is to say, subordinates report to the superior the information; superiors should give instructions to a subordinate. It may form a kind of information circulation, named as feedback mechanism, which can improve the efficiency of information processing. And in this circumstance, employees may realize that what they are doing for corporate is concerned by leaders, and of course, be encouraged to demonstrate their creative power into job performance. Many small companies pay much attention to increasing the Happy Index among their employees which may not produce so much profit, but it enables the whole organization with a perfect condition to fulfill their goals and to maximize the benefits by the good communication system.

\subsection{Improving the incentive mechanism and focusing on mental health}

SMEs should use more flexible and non-coercive means to increase employees' job satisfaction. Thereby it may help employees' responsibility and mission, help improve employees' happiness index which may promote motivation and creativity, and may attract and retain qualified personnel, then achieve the long-term development of SMEs.

\subsubsection{Establishing a performance-based incentive system to stimulate potential capability.}

A recent survey indicated that 79 percent of employees who voluntarily left their jobs did so because of a lack of appreciation[6]. Letting people know you appreciate their work is usually more powerful than giving a raise or bonus alone[7]. When 8,000 recent college graduates were asked what was most important to them as they were deciding where to work, the salary was not the ultimate motivator. They needed enough money to cover their basic needs. However, the majority of participants rated career advancement opportunities as well as interesting and challenging work to be the most important things [8]. Providing advancement opportunities and recognizing achievements are important in attracting and retaining valuable employees. SMEs should make good use of a variety of incentive system to reward extraordinary performance, such as position salary system, the annual salary system and other distribution methods to guarantee the enthusiasm of talented people and also meet the ordinary workers' basic requirement. According to Hewitt Associates (Hewitt Associates 2019-2020), a global human resource consulting and outsourcing firm, there is a tendency that both salary levels and staff turnover rebounded from the bottom. Chinese salary levels in 2020 increased by $8.4 \%$, and in 2019 , only $4.5 \%$; in the Chinese market, the average active turnover rate of employees is $8.3 \%$, in 2011 , up to $16.7 \%$ in 2020 . Many China's human resources management official said that constantly rising turnover rates since 2010 is related to layoffs happened in 2009 from joint venture companies. SMEs need to gradually establish a new performance-based payment system to increase a portion of the newcomers from outside while retaining the existed experienced staff.

\subsubsection{Strengthening the spiritual motivation for employees and focus on the mental health}

SMEs should meet the requirements of employees' survival and career development; invite employees to take part in the business management so as to supply an opportunity for each staff to display their abilities to enhance their job satisfaction and psychological console. 
In order to build a harmonious win-win employee relation, SMEs should pay much attention to employees' health problems, to solve the psychological crisis, re-examine corporate goals, values, and reward structure. In addition to internal training, dinner, vacation travel and family activities will relieve occupational stress, improve employee productivity, and optimize the corporate image, reduce employee turnover rate. To demonstrate the concern of employees, Foxconn changes its salary structure up to 30 percent. but it couldn't stop the tragedy of suicide. That means salary may ease the pressure of life, but may not solve the problems of mental health. To prevent "jumping" or some other tragedy, enterprises must find out the source pressure, and establish warning systems, which proactively identify employees' psychological problems and provide the right solution. SMEs need to carry out an Employee Assistance Program to promote enterprise employee relations from the overview of the psychological contracts.

\subsection{Treating employees fairly and focusing on open communication}

Equity theory looks at how employees' perceptions of fairness affect their willingness to perform. They will try to maintain equity between what they put into the job and what they get out of it, by comparing it to those of others in similar positions. When they perceive inequity, they will try to reestablish fairness in a number of ways. So, in the workplace, perceived inequity may lead to lower productivity, reduced quality, increased absenteeism.

Sometimes organizations try to deal with this by keeping employee salaries secret, but secrets may make things worse. Employees may find information through personal relationships, professional organizations, and other sources. They are like to overestimate the salaries of others, in addition to overestimating their contribution. The best way is to communicate frankly and frequently. Managers must communicate as clearly as possible both the results they expect and the outcomes that will occur [9].

- Create an organizational culture that rewards listening. Employees must feel free to say anything and believe their opinions are valued.

- Remove barriers to open communication. Separate offices, parking areas, and dining rooms for managers only set up barriers. Removing such barriers may reduce some special privileges.

- Ask employees what is important to them. Managers should have frequent stay interviews to find out what matters to employees and what they can do to keep them on the job.

- Avoid vague and ambiguous communication.

To implement such items, managers must carry out management innovation. This means respecting employees, providing interesting work, developing workers' skills, allowing autonomy, decentralizing authority, and rewarding good work.

\section{CONCLUSION}

In short, employee relationship management innovation is to clarify the rights and obligations of two parties, employer and employee. SMEs should upgrade to the organization's strategy to achieve accurate positioning of employee relationship management. Employee relationships may be more harmonious, social security is more perfect only if all staff is more satisfied with their income, with their promotion, with their workplace environment, etc. SMEs' sustainable developments rely on the healthy growth of employee relationship management which provides effective protection during the competition of the market, not only domestic but also the whole world. It is a good way for our Chinese SMEs to learn from western countries and combine with the existing conditions to achieve a win-win strategy at present.

SMEs need to adapt to consciously the economic challenges of globalization according to their characteristics, focusing on practical training and long-term training mechanism. The local government also plays an important role in building up a platform for SMEs and help employees establish a study while working program, introducing the "lifelong learning" concept. Relevant agencies can construct networking for SMEs to attract intelligence.

\section{ACKNOWLEDGMENT}

I would like to express my gratitude to all those who helped me during the writing of this paper.

My deepest gratitude goes first and foremost to the support of Shandong Social Science Planning Project. Without it, this paper could not be reached its present form.

Last my thanks would go to my beloved family for their loving considerations and great confidence on me.

\section{REFERENCES}

[1] F C Anyim D A Ideh. Triangular Employment Relationship Employment Practices and Opportunities for Career Growth of Agency Workers in the Nigerian Banking Industry UDS International Journal of Development,2017,4(1)79-91.

[2] Tyler J. Lane, Shannon Gray, Behrouz HassaniMahmooei et al. Effectiveness of employer financial incentives in reducing time to report worker injury: an interrupted time-series study of two Australian workers' compensation jurisdictions, 2018, 18(1)

[3] LASTAD L, TINNE V E, DEWITTE H. "On the reciprocal relationship between individual job insecurity and job insecurity climate" Career Development International 2016,21(3): 246-261.

[4] SORA B, CABALLER A, JOSE M Job insecurity climate's influence on employees' job attitudes: 
Evidence from two European countries. European Journal of Work \& Organizational

Psychology,2009,18(2): 125-147.

[5] SHOREL M, BOMMERWH, RAOANETAL, Social and economic exchange in the employee-organization relationship: the moderating role of reciprocation wariness[J]. Journal of Managerial Psychology, 2009,24(8):701-721
[6] Maria Elana Duran, "How to Boost Morale at Your Business," U.S. News \&World Report, March 6, 2014

[7] Megan M. Biro, "5 Ways Leaders Rock Employee Recognition,” Forbes, January 13, 2013

[8] Jacquelyn Smith, "What Employers Need to Know about the Class of 2012," Forbes, April 3, 2012

[9] Jason Daley, "In it for the Long Haul," Entrepreneur, February 2013. 